\title{
A 414-year tree-ring-based April-July minimum temperature reconstruction and its implications for the extreme climate events, northeast China
}

\author{
Shanna Lyu ${ }^{1}$, Zongshan $\mathrm{Li}^{2}$, Yuandong Zhang ${ }^{3}$, and Xiaochun Wang ${ }^{1}$ \\ ${ }^{1}$ Center for Ecological Research, Northeast Forestry University, Harbin 150040, China \\ ${ }^{2}$ State Key Laboratory of Urban and Regional Ecology, Research Center for Eco-Environmental Science, \\ Chinese Academy of Sciences, Beijing 100085, China \\ ${ }^{3}$ Key Lab of Forest Ecology and Environment, State Forestry Administration, Institute of Forest Ecology, \\ Environment and Protection, Chinese Academy of Forestry, Beijing 100091, China
}

Correspondence to: Xiaochun Wang (wangxc-cf@nefu.edu.cn)

Received: 15 March 2016 - Published in Clim. Past Discuss.: 22 April 2016

Revised: 21 August 2016 - Accepted: 30 August 2016 - Published: 20 September 2016

\begin{abstract}
A ring-width series was used as a proxy to reconstruct the past 414-year record of April-July minimum temperature at Laobai Mountain, northeast China. The chronology was built using standard tree-ring procedures for providing comparable information in this area while preserving low-frequency signals. By analyzing the relationship between the tree-ring chronology of Korean pine (Pinus koraiensis) and meteorological data, we found that the standard chronology was significantly correlated with the April-July minimum temperature $(r=0.757, p<0.01)$. Therefore, the April-July minimum temperature since 1600 (more than six trees, but the expressed population signal (EPS) is greater than 0.85 since 1660 ) was reconstructed by this tree-ring series. The reconstruction equation accounted for $57.3 \%$ of temperature variation, and it was proved reliable by testing with several methods (e.g., sign test, product mean test, reduction of the error, and coefficient of efficiency). Reconstructed April-July minimum temperature on Laobai Mountain showed six major cold periods (1605-1616, 1645-1677, 1684-1691, 1911-1924, 1930-1942, and 1951-1969) and seven major warm periods $(1767-1785,1787-1793,1795-$ 1807, 1819-1826, 1838-1848, 1856-1873, and 1991-2008) during the past 414 years. The reconstructed low-temperature periods in the 17th and early 18th century were consistent with the Little Ice Age (LIA) in the Northern Hemisphere, and the rate of warming in the 19th century was significantly slower than that in the late 20th century. In addition, the reconstructed series was fairly consistent with the historical
\end{abstract}

and natural disaster records of extreme climate events (e.g., cold damage and frost disaster) in this area. This temperature record provides new evidence of past climate variability, and can be used to predict the climate trend in the future in northeast China.

\section{Introduction}

Global climate change presents major challenges for humans and the natural systems that provide ecosystem services. Consequently, it is urgent to better understand climate change and its forcing mechanisms. Instrumental records are typically less than 100 years and often less than 50 years in most areas of the world. It is necessary to put the present climate regime in the context of long-term perspectives, which forces a reliance on natural proxy records to reconstruct the past climate. Tree rings have been widely applied in global climate change studies and paleoclimate reconstructions on both regional and global scales because they offer accurate and continuous temporal record as well as being are widespread and easily replicated (Corona et al., 2010; Popa and Bouriaud, 2014; Kress et al., 2014).

Northeast China, an area sensitive to global climate change, is located in the ecotone from a temperate to cold temperate zone, belonging to a monsoon fringe area. Due to the interannual instability of monsoon, frequent climate extremes (especially cold damage or frost disaster) seriously 
affect agriculture and forest ecosystems. In addition, previous studies suggest that climate change in northeast China was also linked to the solar activities and global land-sea atmospheric circulation during certain pre-instrumental periods (Chen et al., 2006; Wang et al., 2011; Liu et al., 2013). It is generally accepted that the climate warms during periods of strong solar activity (e.g., the Medieval Warm Period) and cools during periods of low solar activity (e.g., the Little Ice Age; Lean and Rind, 1999; Bond et al., 2001). Recently, the warming in northeast China has been significantly affected by the global warming since the 20th century (Ding and Dai, 1994; Wang et al., 2004; Zhao et al., 2009), which is often caused by a faster rise in night or minimum temperature (Karl et al., 1993; Ren and Zhai, 1998; Tang et al., 2005). To explore whether climate warming is abnormal and predict the future trend of temperature change in this area, we must fully understand the history of climate changes over a long period. However, tree-ring series were rarely used to reconstruct past climate (especially temperature) in this area because of the exceptional hydrothermal conditions. Several temperaturesensitive tree-ring chronologies were developed on Changbai Mountain (e.g., Shao and Wu, 1997; Zhu et al., 2009; Wang et al., 2012; Li and Wang, 2013) and Xiaoxing' an Mountain (Yin et al., 2009; Zhu et al., 2015), but almost no records were obtained for a period of over 250 years, which can reflect the low-frequency climate variations. This limits our understanding of a longer timescale of climate regime in northeast China. Temperature reconstructions are also far from adequate and do not satisfy the demands of scientific research. Therefore, there is a requirement for higher-quality climate reconstructions in a greater number of areas over longer periods and a larger group of climatic indicators for verification in this region. For this reason, more information on regional past climate variations registered in a long-term tree-ring series is needed, and it is important to understand the impacts of climate change on forest ecosystems and the ecosystem services provided to humans in northeast China.

Currently, a significant climate warming (especially the minimum temperature increase) is occurring in northeast China since the 1980s. However, there still remains a lack of long-term climatic records (at least more than 250 years) in this area to explore what is the temperature regime in the past one thousand or half a thousand years and whether the current warming is unprecedented. Therefore, the main objectives of this study are (1) to develop for the first time a more than 400-year ring-width chronology in northeast China; (2) to analyze the regime of temperature variation during the past 4 centuries in northeast China; (3) to identify the recent warming amplitude in a long-term context; and (4) to analyze the extreme low-temperature events. Our new minimum temperature record supplements existing data in northeast China and provides new evidence of past climate variability. There is the potential to better understand future climatic trajectories from these data in northeast China.

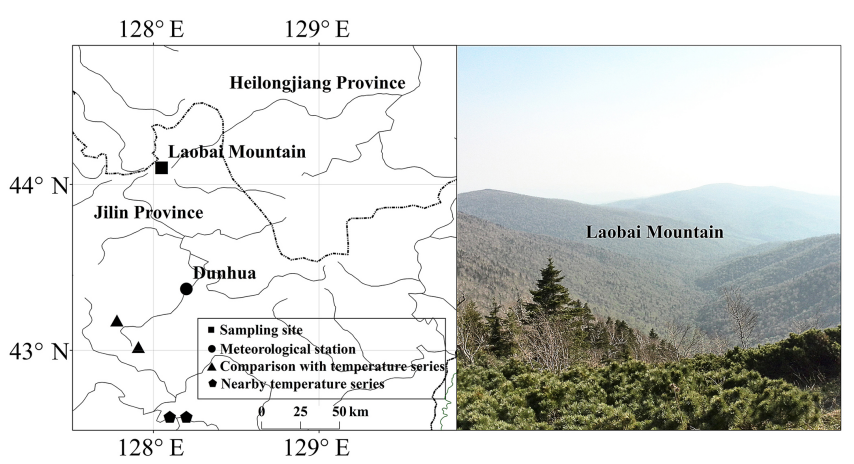

Figure 1. Map of the sampling site, the compared temperature series, nearby temperature series, and the meteorological station in northeast China. The photo shows the sampled site on Laobai Mountain and the remarkable vertical vegetation distribution along altitude changes.

\section{Materials and methods}

\subsection{Study area}

The study area is located at Laobai Mountain $\left(128^{\circ} 03^{\prime} \mathrm{E}\right.$, $44^{\circ} 06^{\prime} \mathrm{N}$ ), the boundary zone between Jilin and Heilongjiang provinces, and is also an ecotone between Changbai and $\mathrm{Xi}$ aoxing' an Mountain. Laobai Mountain is the third highest peak in northeast China and rises to $1650 \mathrm{~m}$ above sea level (a.s.l.). Almost no inhabitants live on or near the mountain, so the forest ecosystem is very well preserved and the native vegetation remains predominantly intact (Fig. 1). Five forest vegetation types from temperate to frigid change with the altitude increase, which is the broad-leaved Quercus mongolica forest below $800 \mathrm{~m}$ a.s.l., the mixed broadleaved Korean pine forest from 800 to $1050 \mathrm{~m}$, dark conifer forest with Picea jezoensis from 1050 to $1350 \mathrm{~m}$, Betula ermanii forest between 1350 and $1640 \mathrm{~m}$, and Pinus pumila forest and subalpine meadow above $1640 \mathrm{~m}$. Plant flora transitions from Changbai Mountain to Xiaoxing' an Mountain. Five tree species were cored in this area, but only Korean pine (Pinus koraiensis) cores were used in this study. Korean pine is a sun-loving plant (shade-tolerant when it is young) and has shallow roots, widely distributed on well-drained wet mountain slopes close to the subalpine timberline where the brown forest soil is covered. The forest vegetation in sampling area is the mixed broadleaved Korean pine forest dominated by Pinus koraiensis, Picea jezoensis, and Abies nephrolepis as well as broadleaf tree species, such as Juglans mandshurica, Fraxinus mandshurica, and Acer mono (Bu et al., 2003).

This region belongs to a temperate continental monsoon climate. Climate data are collected from the nearest meteorological station in Dunhua. The mean annual temperature from 1956 to 2013 is $3.3^{\circ} \mathrm{C}$, with July $\left(20.1^{\circ} \mathrm{C}\right)$ and January $\left(-16.8^{\circ} \mathrm{C}\right)$ being the warmest and the coldest month, respectively. The mean monthly minimum and maximum temperatures are -2.5 and $9.8^{\circ} \mathrm{C}$, respectively. The mean annual 
Table 1. Major statistical characteristics for the chronology of $\mathrm{Pi}$ nus koraiensis on Laobai Mountain.

\begin{tabular}{lrr}
\hline & Std & RES \\
\hline Number of cores & 71 & 71 \\
Time span & $1600-2015$ & $1600-2015$ \\
Mean sensitivity & 0.12 & 0.14 \\
Standard deviation & 0.20 & 0.12 \\
Correlations between trees & 0.22 & 0.28 \\
Correlations within trees & 0.68 & 0.51 \\
Signal-to-noise ratio & 8.72 & 11.81 \\
Autocorrelation order1 & 0.72 & 0.03 \\
Agreement with & 0.90 & 0.92 \\
population chronology & & \\
Variance in first eigenvector & $28.51 \%$ & $30.03 \%$ \\
First year in which & $1660(11)$ & $1685(15)$ \\
EPS $>0.85$ (No. of trees) & & \\
\hline
\end{tabular}

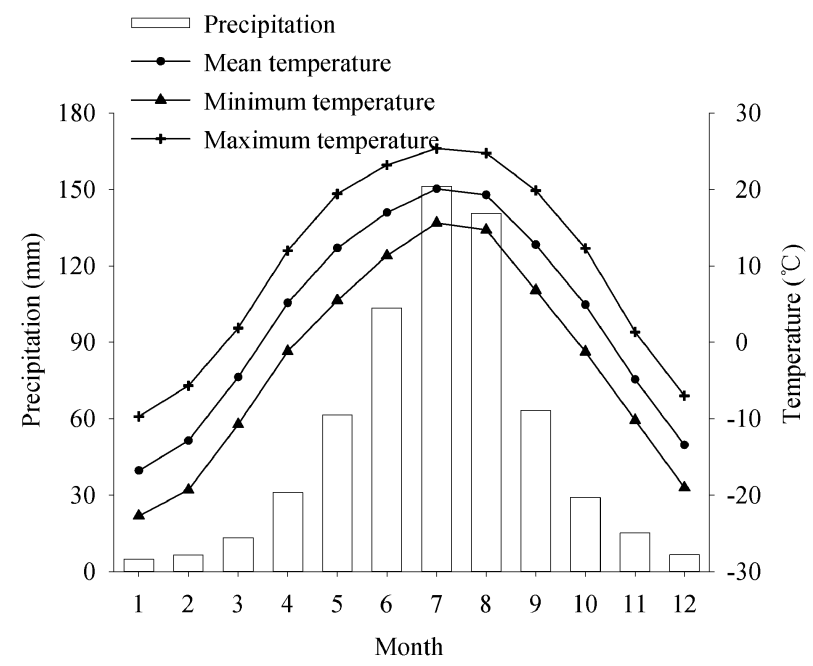

Figure 2. Mean monthly temperature $\left({ }^{\circ} \mathrm{C}\right)$ and total precipitation $(\mathrm{mm})$ at Dunhua meteorological station for the period from 1956 to 2013.

total precipitation is $627 \mathrm{~mm}$, the majority $(63.1 \%)$ of which falls during June-August. The annual frost-free period is approximately $90-110$ days (Fig. 2 ).

\subsection{Tree-ring chronology development}

Korean pine tree-ring samples were obtained from the south slope of Laobai Mountain along an elevational gradient from 950 to $1050 \mathrm{~m}$ from an almost pristine area containing wellpreserved old forests largely uninfluenced by human activity. One or two cores per undamaged tree ( 71 cores from 41 trees) were extracted from cross-slope sides of the trunks at breast height using an increment borer. Cores were air dried, glued firmly to grooved wooden mounts and sanded with progressively finer grade abrasive paper up to 800 grit. Then the samples were cross-dated using a skeleton plot method (Stokes
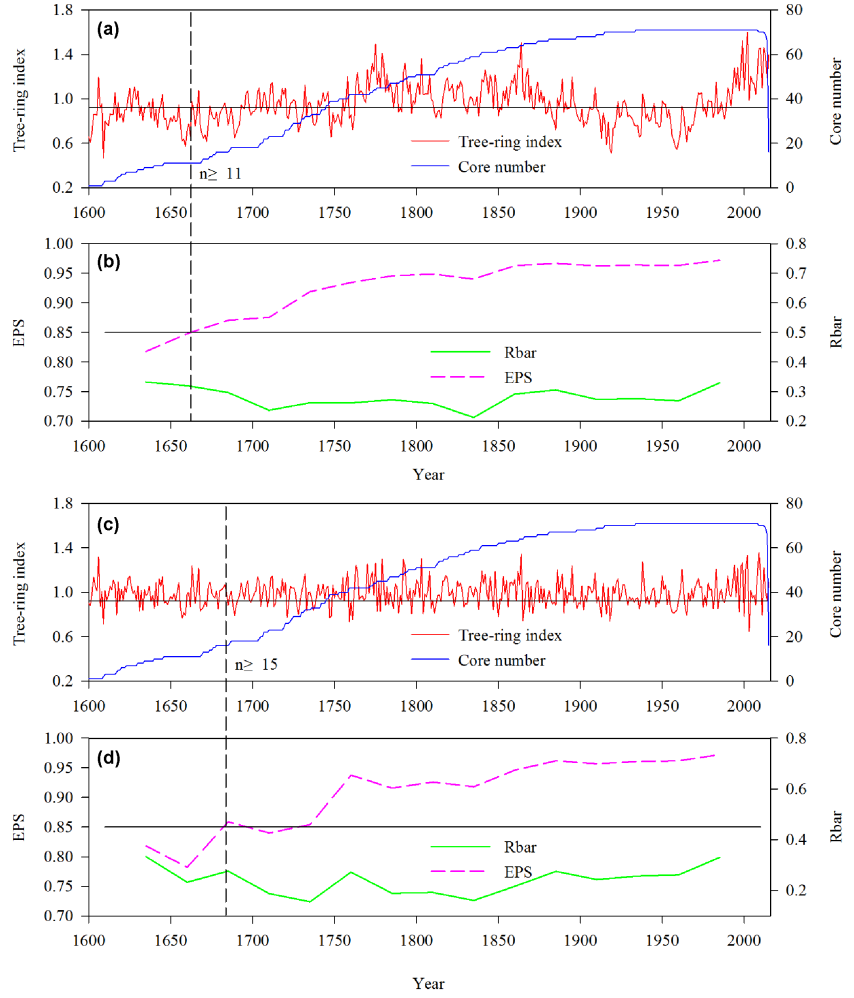

Figure 3. Variations of the std (a) and RES (c) chronology and sample depth and the expressed population signal (EPS) and average correlation between all series (Rbar) of the std (b) and RES (d) chronology from AD 1600 to 2015.

and Smiley, 1968); each tree-ring width was measured with a precision of $0.001 \mathrm{~mm}$ using the Velmex tree-ring width measurement system (Velmex, Inc., Bloomfield, NY, USA). Data were checked for missing or false rings and dating errors using the quality control program COFECHA (Holmes, 1983).

The ARSTAN program was used to detrend and standardize cross-dated tree-ring width series into a tree-ring chronology (Cook, 1985). During this detrending process, to remove biological factors (such as age-related trends) and non-climatic variations and preserve as much low-frequency signal as possible, each ring-width series was fitted with a straight line or negative exponential function. A $67 \%$ cubic smoothing spline with a $50 \%$ cutoff frequency was further used in a few cases when anomalous growth trends occurred. The detrended data from individual tree cores were then averaged using a bi-weight robust mean to develop the standard (std) and residual (RES) chronologies (Cook and Kairiukstis, 1990).

Statistical characteristics for the std and RES chronologies of Pinus koraiensis on Laobai Mountain are shown in Table 1 . These statistic characteristics of tree-ring chronologies contained strong climate signals, common growth-limiting signals, and the amount of different frequency information. 
As shown in Fig. 3, the amplitude of std chronology (Fig. 3a) in low-frequency variability was larger than that in RES chronology (Fig. 3c). This indicated that std chronology preserved more low-frequency signals, while RES chronology reflected high-frequency signals. The mean sensitivity of RES chronology was larger than std chronology, which quantitatively illustrated that RES chronology exhibited more high-frequency climate information than std chronology did (Table 1). The full length of tree-ring series spanned from 1600 to 2015. The expressed population signal (EPS) was used to assess the quality of std chronology (Wigley et al., 1984). A generally acceptable threshold of the EPS was consistently greater than 0.85 from AD 1660 to 2015 (11 trees; Fig. 3b), which affirmed that this is a reliable period. However, although the EPS value from AD 1600 to 1659 was less than 0.85 , it matches a minimum sample depth of six trees in this segment. It is very important to extend the reconstruction tree-ring chronology as possible as we could because of a few long climate reconstructions in this area. Therefore, we kept this part from 1600 to 1659 to be used in the reconstruction. In addition, the std chronology was used in the subsequent analyses to obtain more low-frequency signals.

\subsection{Climate data and statistical methods}

Meteorological data were obtained from the National Meteorological Information Center (http://data.cma.cn/). Considering the proximity to sampling sites and climate record length, climate data from Dunhua meteorological station $\left(43^{\circ} 22^{\prime} \mathrm{N}, 128^{\circ} 12^{\prime} \mathrm{E}\right.$; elevation 524.9 m a.s.l.; 1956-2013) were selected to identify climate signals in the tree-ring series. The climate variable included monthly total precipitation, mean maximum temperature $\left(T_{\max }\right)$, mean temperature $\left(T_{\text {mean }}\right)$, and mean minimum temperature $\left(T_{\min }\right)$. Months from the previous July to current August were selected for the analysis of the relationship between climate variables and Korean pine growth.

To identify climate-growth relationships of Korean pine on Laobai Mountain, a Pearson's correlation was performed between climate variables and tree growth. The stability and reliability of the reconstruction equation was assessed by the split-period calibration and verification analyses (Fritts, 1976; Cook and Kairiukstis, 1990) for the two periods 19561984 and 1985-2013. The Pearson's correlation coefficient $(r), R$ square $\left(R^{2}\right)$, sign test (ST), the reduction of the error (RE), the coefficient of efficiency (CE), and the product means test (PMT) are the tools used to verify the results. All statistical analyses presented in this paper were performed using a commercial software, SPSS12.0 (SPSS, Inc., Chicago, IL, USA).
Table 2. Correlation coefficients between the std chronology and the climate data of different month combinations during the common period of 1956-2013. Months are given as follows: c4-c7 current April to July; c4-c8 - current April to August; c4-c9 - current April to September; c5-c7 - current May to July; c5-c8 - current May to August; c5-c9 - current May to September; c6-c8 current June to August; c6-c9 - current June to September; p7-c8 - previous July to current August.

\begin{tabular}{lrrr}
\hline Months & $T_{\text {mean }}$ & $T_{\min }$ & $T_{\max }$ \\
\hline c4-c7 & $0.577^{*}$ & $0.757^{*}$ & 0.177 \\
c4-c8 & $0.557^{*}$ & $0.717^{*}$ & 0.183 \\
c4-c9 & $0.599^{*}$ & $0.726^{*}$ & 0.217 \\
c5-c7 & $0.556^{*}$ & $0.749^{*}$ & 0.198 \\
c5-c8 & $0.522^{*}$ & $0.691^{*}$ & 0.198 \\
c5-c9 & $0.587^{*}$ & $0.709^{*}$ & 0.236 \\
c6-c8 & $0.447^{*}$ & $0.634^{*}$ & 0.199 \\
c6-c9 & $0.535^{*}$ & $0.671^{*}$ & 0.241 \\
p7-c8 & $0.586^{*}$ & $0.682^{*}$ & 0.230 \\
\hline
\end{tabular}

* Significant at the 0.01 level (two-tailed).

\section{Results and discussion}

\subsection{Climate-radial growth relationship}

Relationships between the std and RES chronologies and monthly climate data in Dunhua were shown in Fig. 4. Temperatures were more crucial to Korean pine growth compared with precipitation. In contrast, the correlation coefficients between Korean pine chronologies and mean minimum temperature were positive and higher than those for maximum and mean temperature. The significant correlation months between std chronology (Fig. 4a) and mean minimum temperature were not found in the RES chronology (Fig. 4b). This indicated that the std chronology recorded the minimum temperature signals in low frequency but not at high frequencies. Different combinations of months were also considered (Table 2). The best-correlated 3-month season, April-July $(r=0.757, p<0.0001)$, was then selected for temperature reconstruction of the mean minimum temperature (MMT; Table 2).

It was generally accepted that extreme temperatures limited tree growth at the tree line or at high-latitude forests, especially spring or early summer minimum temperature (Wilson and Luckman, 2002; Körner and Paulsen, 2004; Porter et al., 2013; Yin et at., 2015). Moreover, $T_{\max }, T_{\text {mean }}$, and $T_{\min }$ during the observed period of 1956-2013 illustrated similar interannual variations (Fig. 5), while the increasing trend in $T_{\min }$ was much higher than $T_{\text {mean }}$ and $T_{\max }$, especially since 1976. This phenomenon was consistent with the results in Karl et al. (1993), Ren et al. (1998), and Tang et al. (2005). They indicated that climate warming over past decades was mostly owing to the faster rise of night or minimum temperatures. This seemed to be the case in northeast China as 

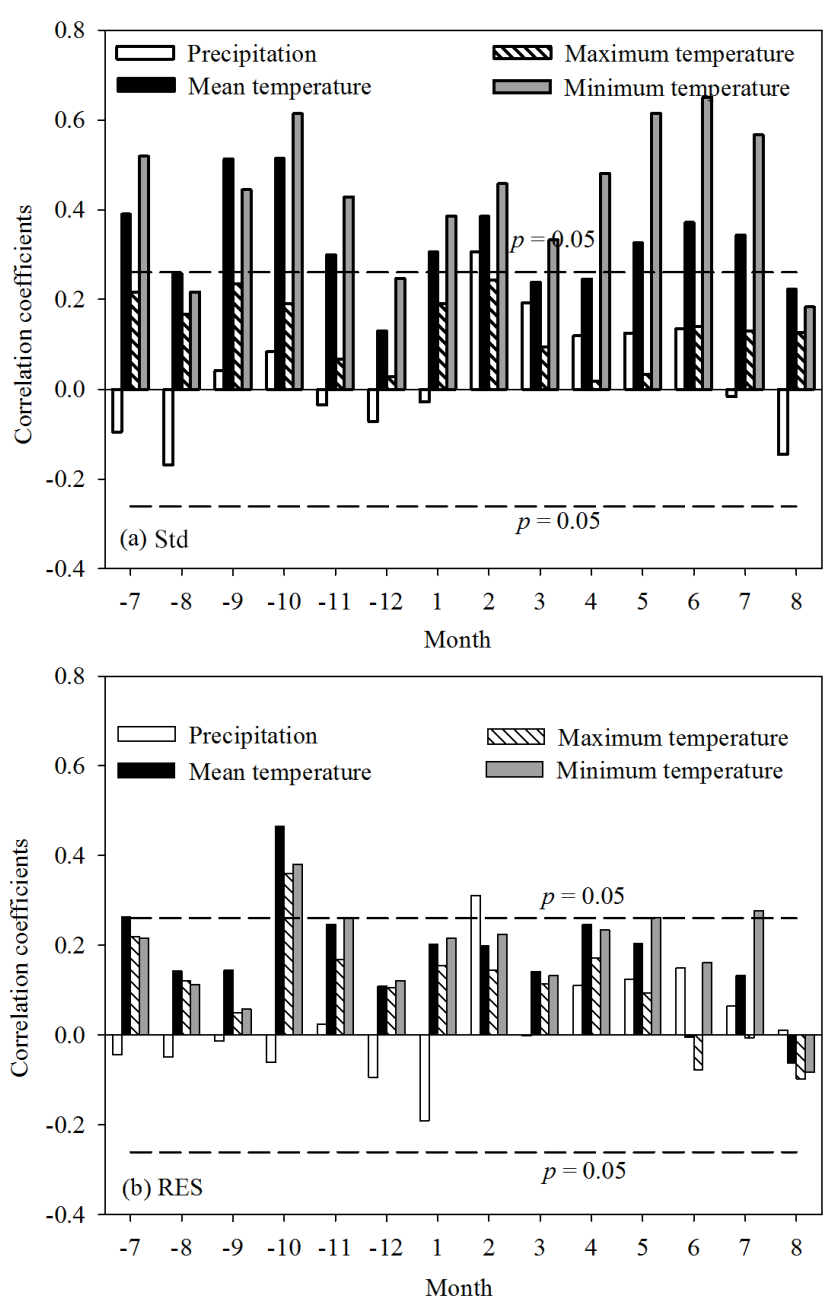

Figure 4. Correlations between the monthly mean meteorological data (including mean temperature, mean maximum temperature, mean minimum temperature, and total precipitation) from Dunhua meteorological station (1956-2013) and (a) the std chronology and (b) RES chronology. The dashed horizontal line represents the $95 \%$ confidence limit.

well. Based on the relationship between std chronology and climate data, we found that the minimum April-July temperature played more important roles in limiting Korean pine radial growth on Laobai Mountain compared with the maximum and mean temperatures. This also meant that less warm and wet conditions in this area were suitable for Korean pine growth.

This may have two reasons. One, the sampling site was located at high elevations close to the upper limit of the Korean pine distribution, which may cause tree growth to be more sensitive to minimum temperature (Szeicz and MacDonald, 1995; D'Arrigo et al., 2009; Li et al., 2011; Yu et al., 2011; Flower and Smith, 2012). High minimum temperatures in the early growing season can inhibit frost damage and thus allow the formation of a wider ring (Wu, 1990; Akkemik,

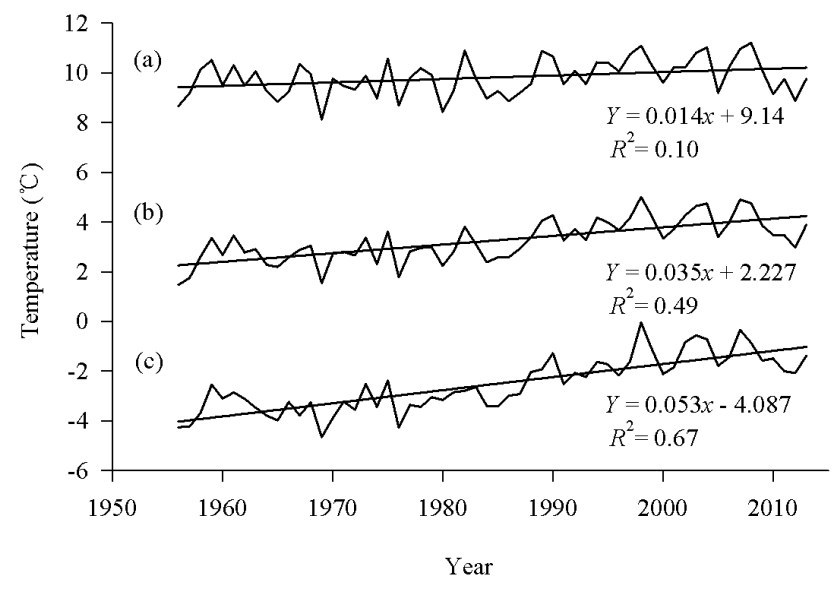

Figure 5. Interannual variation of the mean maximum (a), mean (b), and mean minimum temperatures (c) from 1956 to 2013. The straight line represents the fitted trend line.

2000; Mäkinen et al., 2003). High nighttime temperatures can also promote tree respiration and enhance physiological activities, thereby producing more auxin, promoting cell enlargement and forming a wider ring in growing season (Fritts et al., 1976). Increasing temperature may allow trees to conduct photosynthesis at the early stage of the growing season, which might produce more auxin. A crucial growth period of Korean pine in every year was from April to July. During this period, temperature could have direct effects on the photosynthesis rate, cambium activity, and respiration efficiency, etc., which affect the formation of ring width (Li et al., 2000; Yu et al., 2011). Therefore, Korean pine radial growth was positively correlated with the average minimum temperature from April to July.

\subsection{Minimum temperature reconstruction}

Based on the above analysis, a linear regression equation was established to reconstruct the April-July MMT. The transfer function was as follows:

$$
\begin{aligned}
Y & =2.987 X_{t}+4.829 \\
(N & =58, R=0.757 R^{2}=0.573, R_{\mathrm{adj}}^{2}=0.565, \\
F & =75.161, p<0.0001),
\end{aligned}
$$

where $Y$ is the April-July MMT and $X$ is the tree-ring index of the Korean pine std chronology at year $t$. As shown in Fig. 6a, the reconstructed values closely tracked the observed temperature. The calibration and verification statistics were shown in Table 3. Parameters of the split-sample validation periods indicated that the reconstruction equation was stable over the whole period. Positive RE and CE values revealed a useful paleoclimatic information (Cook et al., 1999). Significant results of std and PMT indicated a good agreement between the actual and reconstructed data. 
Table 3. Calibration and verification statistics of the reconstruction equation for the common period of 1956-2013.

\begin{tabular}{lrrrrrrrr}
\hline Calibration & $R$ & $R^{2}$ & Verification & $R$ & $\begin{array}{r}\text { Reduction } \\
\text { of error }\end{array}$ & $\begin{array}{r}\text { Coefficient } \\
\text { of efficiency }\end{array}$ & Sign test & $\begin{array}{r}\text { Product } \\
\text { means test }\end{array}$ \\
\hline $\begin{array}{l}\text { Whole section } \\
1956-2013\end{array}$ & $0.757^{\mathrm{b}}$ & $0.573^{\mathrm{b}}$ & - & - & - & - & - & - \\
$\begin{array}{l}\text { Front section } \\
(1956-1984)\end{array}$ & $0.414^{\mathrm{a}}$ & $0.171^{\mathrm{a}}$ & $\begin{array}{l}\text { Back section } \\
(1985-2013)\end{array}$ & $0.632^{\mathrm{b}}$ & $0.738^{\mathrm{b}}$ & $0.446^{\mathrm{b}}$ & $(20,9)^{\mathrm{a}}$ & $4.586^{\mathrm{b}}$ \\
$\begin{array}{l}\text { Back section } \\
(1985-2013)\end{array}$ & $0.632^{\mathrm{b}}$ & $0.400^{\mathrm{b}}$ & $\begin{array}{l}\text { Front section } \\
(1956-1984)\end{array}$ & $0.414^{\mathrm{a}}$ & $0.738^{\mathrm{b}}$ & $0.634^{\mathrm{b}}$ & $(22,7)^{\mathrm{b}}$ & $6.099^{\mathrm{b}}$ \\
\hline
\end{tabular}

a Significant at the 0.05 level (two-tailed). ${ }^{\mathrm{b}}$ Significant at the 0.01 level (two-tailed).
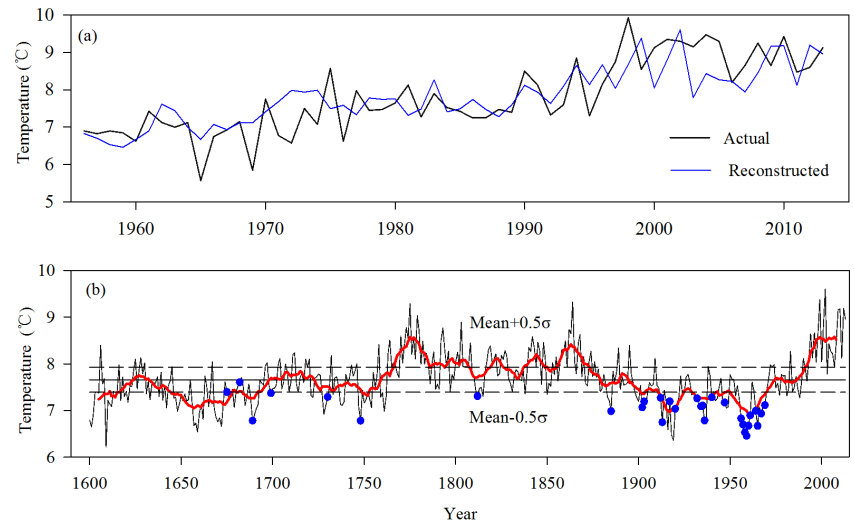

Figure 6. (a) Actual (black line) and reconstructed (blue line) April-July minimum temperature for the common period of 19562013; (b) reconstruction of April-July minimum temperature on Laobai Mountain for the last 414 years. The smoothed line indicates the 11-year moving average, and blue dots represent minimum freezing events.

However, the first difference correlation (not shown) between the std chronology and temperature did not exceed the $95 \%$ confidence level. This confirmed that the std chronology might capture the low-frequency variability better than high-frequency variability. In addition, the correlation coefficient between the first-order difference series of the actual and reconstructed values was not significant at the 0.05 level $(r=0.12, p>0.05)$; hence, this reconstructed minimum temperature series was more consistent with the observed series at low-frequency variability. The final calibration equation accounted for $57.3 \%$ of the total variance $(p<0.0001)$ and passed all calibration and verification statistical requirements. Hence, this equation was reliable and allowed for the accurate reconstruction of the April-July MMT on Laobai Mountain.

\subsection{Temperature variations from AD 1600 to 2013}

The reconstructed average April-July MMT variations since AD 1600 and its 11-year moving average were shown in
Fig. 6b. The 11-year moving average of the reconstructed series was used to obtain low-frequency information and analyze temperature variability in this region. The mean value of the 414-year reconstructed temperature was $7.66^{\circ} \mathrm{C}$, with a standard deviation of $\pm 0.53^{\circ} \mathrm{C}$. The warm and cold periods were defined when temperatures exceeded the mean value plus and minus 0.5 times standard deviation, respectively (Fig. 6b). The reconstructed April-July MMT series exhibited six cold and seven warm periods. The longest cold period lasted from AD 1645 to 1677 (33 years), with an average temperature of $0.5^{\circ} \mathrm{C}$ below the mean value. The longest warm period, however, lasted from AD 1767 to 1785 (19 years), and the average temperature was $0.69{ }^{\circ} \mathrm{C}$ above the mean value (Table 4). Four cold (1605-1616, 1645-1677, 1911-1924, and 1951-1969) and warm (1795-1807, 18381848, 1856-1873, and 1991-2008) periods were consistent with other results of tree-ring reconstructions in northeast China (Shao and Wu, 1997; Yin et al., 2009; Wang et al., 2012; Zhu et al., 2015). In addition, two cold periods (16451677 and 1684-1691) were consistent with the Maunder Minimum (1645-1715), an interval of decreased solar irradiance (Bard et al., 2000). The cold period 1645-1677 also appeared in other proxy records of reconstructed temperatures, which coincided with the Little Ice Age (LIA) in the Northern Hemisphere (Lin et al., 2004; Wang et al., 2006; Hong et al., 2009). Cold conditions during the 17th century and the rapid warming during the mid-19th and late 20th century in northeast China was present in this series, suggesting it could be a good proxy for regional temperature variations in northeast China.

To further evaluate the reliability of this reconstruction, we compared our reconstruction series with two nearby treering-based reconstruction temperature series from Dunhua (Li and Wang, 2013; Fig. 7a) and Changbai Mountain (Zhu et al., 2009; Fig. 7b) and the Northern Hemisphere temperature reconstruction (D'Arrigo et al., 2006; Fig. 7d). Interestingly, a significant negative correlation $(r=-0.18, p<0.01)$ between our reconstruction (Fig. 7c) and the Northern Hemisphere temperature reconstruction (D'Arrigo et al., 2006) was found (Fig. 7d), while our reconstruction of AprilJuly MMT had similar variations in the April-September 
Table 4. Cold and warm periods based on the 11-year moving average April-July mean minimum temperature on Laobai Mountain during AD 1600-2013.

\begin{tabular}{lrrrrrrr}
\hline & \multicolumn{3}{c}{ Cold period } & & \multicolumn{3}{c}{ Warm period } \\
\cline { 2 - 3 } \cline { 7 - 8 } Rank & Period & Year & Mean $\left({ }^{\circ} \mathrm{C}\right)$ & & Period & Year & Mean $\left({ }^{\circ} \mathrm{C}\right)$ \\
\hline 1 & $1605-1616$ & 12 & 7.41 & & $1767-1785$ & 19 & 8.35 \\
2 & $1645-1677$ & 33 & 7.19 & & $1787-1793$ & 7 & 8.01 \\
3 & $1684-1691$ & 8 & 7.19 & & $1795-1807$ & 13 & 8.00 \\
4 & $1911-1924$ & 14 & 7.09 & & $1819-1826$ & 8 & 8.07 \\
5 & $1930-1942$ & 13 & 7.27 & & $1838-1848$ & 11 & 8.13 \\
6 & $1951-1969$ & 19 & 7.08 & & $1856-1873$ & 18 & 8.13 \\
7 & & & & & $1991-2008$ & 18 & 8.38 \\
\hline
\end{tabular}

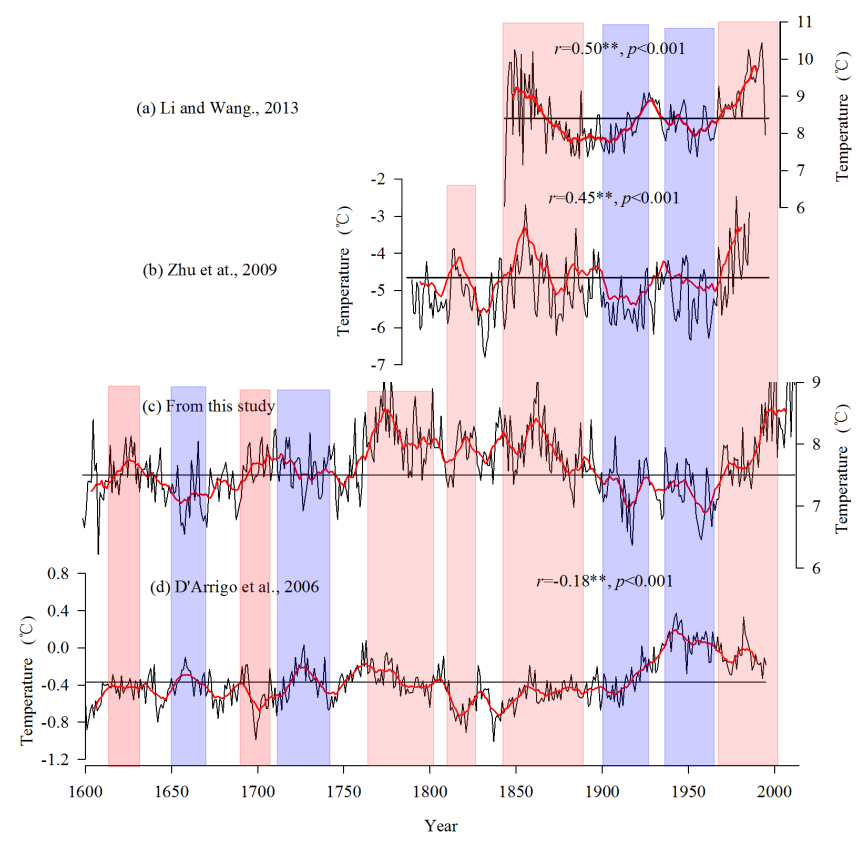

Figure 7. (a) April-September mean minimum temperature reconstructed by Li and Wang (2013) in Dunhua, (b) February-April temperature established by Zhu et al. (2009) on Changbai Mountain, (c) April-July minimum temperature on Laobai Mountain, and (d) Northern Hemisphere extratropical temperature (D'Arrigo et al., 2006). Black lines denote temperature reconstruction values, and red color lines indicate the 11-year moving average.

temperature reconstruction in Dunhua $(r=0.50, p<0.01$; Fig. 7a) and the February-April temperature reconstruction on Changbai Mountain ( $r=0.45, p<0.01$; Fig. 7b). The three temperature series exhibited significantly lowtemperature periods during the 1950s-1970s, which coincided with a slight decrease in solar activity from AD 1940 to 1970 (Beer et al., 2000; Fig. 7).

It was widely believed that the LIA in China exhibited three cold periods in the 15th, 17th, and 19th centuries (Wang et al., 2003), and this was confirmed by our reconstruction series (Fig. 7c and Table 4). The first cold period in our series
Table 5. Cold damage or frost disaster events recorded in historical archives in Heilongjiang Province since 1675 (Sun et al., 2007).

\begin{tabular}{lrrr}
\hline 17 th century & 18th century & 19th century & 20th century \\
\hline 1675 & 1730 & $1800-1801$ & $1901-1903$ \\
1682 & 1746 & $1812-1813$ & $1909-1915$ \\
1689 & 1749 & $1830-1832$ & 1917 \\
1699 & 1748 & $1878-1879$ & 1920 \\
& 1755 & 1885 & $1925-1926$ \\
& 1757 & & $1931-1932$ \\
& & & $1934-1936$ \\
& & & $1939-1943$ \\
& & & 1947 \\
& & & $1950-1969$ \\
& & & $1971-1991$ \\
\hline
\end{tabular}

was less obvious, while the second one was the most obvious of all. A different beginning and ending year of the second cold period in our reconstruction was found (Fig. 7c and Table 4). In addition, there existed a regional difference for the third cold period, that is, it was obvious in south China, while had the opposite phase in northeast China (Wang et al., 1998; Wang et al., 2003). The third cold period in 19th century was not obvious in our reconstruction, which was consistent with Wu (2013) and Wang et al. (1998). This also led to a bad match with the Northern Hemisphere temperature (D'Arrigo et al., 2006). Another notable feature in Fig. 7 was a sharp temperature increase since the $1980 \mathrm{~s}$, and temperature rose to a peak in the early 2000s. The temperature increase in this area was consistent with the report from the Intergovernmental Panel on Climate Change (IPCC, 2007). This series displayed similar patterns of low-frequency variations suggesting that the reconstructed temperature in northeast China was significantly correlated with large-scale variations (Fig. 7).

Unfortunately, three compared temperature series also showed dissimilar variations in some cold and warm years (Fig. 7). This might be due to differences in reconstructed temperature months, parameters (such as mean, minimum, and maximum temperature), and habitat conditions in differ- 
ent sampling areas. Recent studies suggested that the mean, minimum, and maximum temperature variations were often asymmetric (Karl et al., 1993; Xie and Cao, 1996; Wilson and Luckman, 2002, 2003; Gou et al., 2008). Global warming over the past decades was mostly owing to the faster rise of night or minimum temperatures but not maximum temperature. The unsynchronized variability among mean, minimum, and maximum temperatures was found at Dunhua meteorological station (Fig. 5). The sampled site was located at a border zone between Jilin and Heilongjiang provinces, further north than Changbai Mountain. Meanwhile, some differences in the reconstructed temperature series were explained reasonably well from the comparison with analogous regions. Consequently, these findings could reveal more characteristics of regional climate variations and provide reliable data for larger-scale climate reconstructions in northeast China.

\subsection{Detection of northeast-wide cold damage or frost disaster events}

As the minimum temperature approached or fell below the freezing point, it may have limited biological activity and growth. Therefore, years with low temperatures were often accompanied by cold damage or severe frost events. The evidence from historical documents (Sun et al., 2007) showed that cold damage or frost disaster events have occurred in Heilongjiang Province since 1675 (Table 5). Extremely cold damage or frost disaster events were in good agreement with eight low-temperature years $(1675,1682,1689,1699,1730$, 1748, 1812, and 1885 in Fig. 6b and Table 4) in reconstructed April-July MMT series during the 1600s-1800s. At the beginning of 20th century, three severe frost periods occurred in the periods 1909-1918, 1934-1945, and 1956-1972 in Heilongjiang Province (Sun et al., 2007) and were represented in our reconstruction (Fig. 6b and Table 4). In addition, other low-temperature years in our reconstruction corresponded to extreme frost disaster events occurred in the periods 1902-1903, 1912-1914, 1920, 1932, 1934-1936, 1940, 1947, 1956-1961, 1964-1965, 1967, and 1969 (Fig. 6b and Table 4). The results revealed that 27 of the 30 cold damage or frost disaster events corresponded to the April-July MMT lower than the 27-year moving average, while the remaining three events corresponded to higher than April-July MMT values. In contrast, we found a decreasing trend in the annual extreme low-temperature frequency and cold damage or severe frost events with the warming since the 1980s. In summary, the reconstructed April-July MMT on Laobai Mountain strongly revealed the cold damage or frost disaster events in the past 414 years.

\section{Conclusions}

A significant positive correlation between the tree-ring width of Korean pine and the April-July MMT was found on Laobai Mountain, northeast China, and the April-July MMT was reconstructed for the past 414 years (1600-2013). The reconstructed and instrumental temperature series exhibited coherence over the common periods. The reconstructed series showed interannual to multidecadal temperature variations over the past 414 years. The cold and warm periods of the reconstructed minimum temperature record were also observed in historical documents and several proxy temperature records in northeast China. The most notable feature of the reconstructed series was obviously a rapid warming trend since the 1980s, which was also confirmed by other reconstructed temperature series. Additionally, the correspondence between the low-temperature years and the historical cold damage or severe frost events demonstrated the potential relationship between April and July MMT and extreme cold events. This temperature record may provide new and valuable information for the longest temperature variation period in northeast China.

\section{Data availability}

The April-July minimum reconstruction on Laobai Mountain will be available in the Supplement of the original publication (http://www.ncdc.noaa.gov/data-access/ paleoclimatology-data/datasets/tree-ring) and all the data published in this study are available for noncommercial scientific purposes.

\section{The Supplement related to this article is available online at doi:10.5194/cp-12-1879-2016-supplement.}

Acknowledgements. This research was supported by the National Natural Science Foundation of China (nos. 41471168 and 31370463), the Key Project of the Special Focus on "Global Change and Mitigation" of the China National Key Research and Development Plan (2016YFA0600800), the Program for Changjiang Scholars and Innovative Research Team in University (IRT-15R09), and the Program for New Century Excellent Talents in University (NCET-12-0810). We greatly appreciate the three anonymous referees for their constructive and helpful comments in revising and improving our manuscript a lot. We thank the staff of Laobai Mountain Forestry Bureaus for their assistance in the field. Meanwhile, we greatly appreciate Neil Pederson at Harvard Forest, Harvard University, for his assistance in English-language editing of parts of the paper.

Edited by: J. Guiot

Reviewed by: three anonymous referees 


\section{References}

Akkemik, Ü.: Dendroclimatology of umbrella pine (Pinus pinea $\mathrm{L}$.) in Istanbul, Turkey, Tree-Ring Bull., 56, 17-20, 2000.

Bard, E., Raisbeck, G., Yiou, F., and Jouzel, J.: Solar irradiance during the last 1200 years based on cosmogenic nuclides, Tellus B, 52, 985-992, 2000.

Beer, J., Mende, W., and Stellmacher R.: The role of the sun in climatic forcing, Quaternary Sci. Rev., 19, 403-415, 2000.

Bond, G., Kromer, B., Beer, J., Muscheler, R., Evans, M. N., Showers, W., Hoffmann, S., Lotti-Bond, R., Hajdas, I., and Bonani, G.: Persistent solar influence on north Atlantic climate during the Holocene, Science, 294, 2130-2136, 2001.

Bu, Z. J., Wang, S. Z., Lang, H. Q., and Guo, K.Q.: Vegetation vertical zone spectrum and its features on southern slope of Laobai Mountain in Huangnihe Nature Reserve, J. Mountain Sci., 21, 80-84, 2003.

Chen, Z., He, X., Chen, W., Shao,X., Sun,Y., and Tao, D.: Solar activity, global surface air temperature anomaly and Pacific Decadal Oscillation signals observed in urban outskirts tree ring records from Shenyang, China, Adv. Space Res., 38, 2272-2284, 2006.

Cook, E. R. and Kairiukstis, L. A.: Methods of dendrochronology: applications in the environmental sciences, Kluwer Academic Publishers, Dordrecht, 1990.

Cook, E. R., Meko, D. M., Stahle, D. W., and Cleaveland, M. K.: Drought reconstruction for the continental United States, J. Climate, 12, 1145-1162, 1999.

Cook, E. R.: A time series analysis approach to tree-ring standardization, University of Arizona Press, Tucson, 1985.

Corona, C., Guiot, J., Edouard, J. L., Chalié, F., Büntgen, U., Nola, P., and Urbinati, C.: Millennium-long summer temperature variations in the European Alps as reconstructed from tree rings, Clim. Past, 6, 379-400, doi:10.5194/cp-6-379-2010, 2010.

D'Arrigo, R., Wilson, R., and Jacoby, G.: Northern Hemisphere Tree-Ring-Based STD and RCS Temperature Reconstructions, J. Geophys. Res, 111, D03103, doi:10.1029/2005JD006352, 2006.

D’Arrigo, R., Jacoby, G., Buckley, B., Sakulich, J., Frank, D., Wilson, R., Curtis, A., and Anchukaitis, K.: Tree growth and inferred temperature variability at the North American arctic treeline, Global Planet. Change, 65, 71-82, 2009.

Ding, Y. and Dai, X.: Temperature Variation in China during the Last 100 years, Meteorology, 20, 19-26, 1994.

Flower, A. and Smith, D. J.: A dendroclimatic reconstruction of June-July mean temperature in the northern Canadian Rocky Mountain, Dendrochronologia, 29, 55-63, 2012.

Fritts, H. C.: Tree rings and climate, Academic Press Inc. (London) Ltd., London, UK, 1976.

Gou, X., Chen, F., Yang, M., Gordon, J., Fang, K., Tian, Q., and Zhang, Y.: Asymmetric variability between maximum and minimum temperatures in Northeastern Tibetan Plateau: evidence from tree rings, Sci. China Ser. D, 51, 41-55, 2008.

Holmes, R. L.: Computer-assisted quality control in tree-ring dating and measurement, Tree-ring Bulletin., 43, 69-78, 1983.

Hong, B., Liu, C., Lin, Q., Yasuyuki, S., Ling, X., Wang, Y., Zhu, Y., and Hong, Y.: Temperature evolution of the last 14000 years of the Hani peat $\delta^{18} \mathrm{O}$, Sci. China Ser. D, 39, 626-637, 2009.
IPCC: Climate Change 2007: The Physical Science Basis, Cambridge University Press, Cambridge, UK and New York, USA, 2007.

Karl, T. R., Jones, P. D., Knight, R. W., Kulas, G., Plummer, N., Razuvayev, V., Gallo, K. P., Lindseay, J., Charlson, R. J., and Peterson, T. C.: A new perspective on recent global warming: asymmetric trends of daily maximum and minimum temperature, B. Am. Meteorol. Soc., 74, 1007-1023, 1993.

Körner, C. and Paulsen, J.: A world-wide study of high altitude treeline temperatures, J. Biogeogr., 31, 713-732, doi:10.1111/j.1365-2699.2003.01043.x, 2004.

Kress, A., Hangartner, S., Bugmann, H., Büntgen, U., Frank, D. C., Leuenberger, M., Siegwolf, R. T. W., and Saurer, M.: Swiss tree rings reveal warm and wet summers during medieval times, Geophys. Res. Lett., 41, 1732-1737, 2014.

Lean, J. and Rind, D.: Evaluating sun-climate relationships since the Little Ice Age, J. Atmos. Sol. Terr. Phys., 61, 25-36, 1999.

Li, G., Bai, F., and Sang, W.: Different responses of radial growth to climate warming in Pinus koraiensis and Picea jezoensis var. komarovii at their upper elevational limits in Changbai Mountain, China, Chinese J. Plant Ecol., 35, 500-511, 2011.

Li, J., Yuan, Y., and You, X.: Research and application of dendrohydrology, Science Press, Beijing, 2000.

Li, M. and Wang, X.: Climate-growth relationships of three hardwood species and Korean pine and minimum temperature reconstruction in growing season in Dunhua, China, J. Nanjing Forestry Univ. (Natural Sci. Ed.), 37, 29-34, 2013.

Lin, Q., Leng, X., and Hong, B.: The Peat Record of 1 ka of Climate Change in Daxing Anling, B. Mineral. Petrol. Geochem., 3, 1518, 2004.

Liu, Y., Wang, Y., Li, Q., Sun, J., Song, H., Cai, Q., Zhang, Y., Yuan, Z., and Wang, Z.: Reconstructed May-July mean maximum temperature since 1745 AD based on tree-ring width of Pinus tabulaeformis in Qianshan Mountain, China, Palaeogeogr. Palaeocl., 388, 145-152, 2013.

Mäkinen, H., Nöjd, P., Kahle, H. P., Neumann, U., Tveite, B., Mielikäinen, K., Röhle, H., and Spiecker, H.: Large-scale climatic variability and radial increment variation of Picea abies (L.) Karst. in central and northern Europe, Trees, 17, 173-184, 2003.

Popa, I. and Bouriaud, O.: Reconstruction of summer temperatures in Eastern Carpathian Mountain (Rodna Mts, Romania) back to AD 1460 from tree-rings, Int. J. Climatol., 34, 871-880, 2014.

Poretor, T. J., Pisaric, M. F., Kokelj, S. V., and deMontigny, P.: A ring-width-based reconstruction of June-July minimum temperatures since AD 1245 from white spruce stands in the Mackenzie Delta region, northwestern Canada, Quaternary Res., 80, 167179, 2013.

Ren, F. and Zhai, P.: Study on Changes of China's Extreme Temperatures During 1951-1990, Sci. Atmos. Sin., 22, 217-227, 1998.

Shao, X. and Wu, X.: Reconstruction of climate change on Changbai Mountain, Northeast China using tree-ring data, Quaternary Sci., 1, 76-83, 1997.

Stokes, M. A. and Smiley, T. L.: Tree-ring dating, the University of Chicago Press, Chicago and London, 1968.

Sun, Y.: Grand dictionary of China meteorological disasters: Volume Heilongjiang, China Meteorological Press, Beijing, 2007.

Szeicz, J. M. and MacDonald, G. M.: Dendroclimatic reconstruction of summer temperatures in northwestern Canada since A.D. 
1638 based on age-dependent modelling, Quaternary Res., 44, 257-266, 1995.

Tang, H., Zhai, P., and Wang, Z.: On Change in Mean Maximum Temperature, Minimum Temperature and Diurnal Range in China During 1951-2002, Climatic Environ. Res., 10, 728-735, 2005.

Wang, J., Chen, F., Yang, B., and Chen, J.: New advances in research on the Little Ice Age climate change, Adv. Climate Change Res., 2, 21-27, 2006.

Wang, S., Liu, J., and Zhou, J.: The Climate of Little Ice Age Maximum in China, J. Lake Sci., 15, 369-379, 2003.

Wang, S., Ye, J., and Gong, D.: Climate in China during the little ice age, Quaternary Sci., 1, 54-64, 1998.

Wang, W., Zhang, J., Dai, G., Wang, X., Han, S., Zhang, H., and Wang, Y.: Variation of autumn temperature over the past 240 years in Changbai Mountain of Northeast China: A reconstruction with tree- ring records, China J. Ecol., 31, 787-793, 2012.

Wang, X., Brown, P. M., Zhang, Y., and Song L.: Imprint of the Atlantic Multidecadal Oscillation on tree-ring widths in Northeastern Asia since 1568, PLoS ONE, 6, e22740, doi:10.1371/journal.pone.0022740, 2011.

Wang, Z., Ding, Y., He J., and Yu, J.: An updating analysis of the climate change in China in recent 50 years, Ac. Meteorol. Sin., 62, 228-236, 2004.

Wigley, T. M. L., Briffa K. R., and Jones P. D.: On the average value of correlated time series, with applications in dendroclimatology and hydrometeorology, J. Clim. Appl. Meteorol., 23, 201-213, 1984.

Wilson, R. J. S. and Luckman, B. H.: Tree-ring reconstruction of maximum and minimum temperatures and the diurnal temperature range in British Columbia, Canada, Dedrochronologia, 20, $1-12,2002$.

Wilson, R. J. S. and Luckman, B. H.: Dendroclimatic reconstruction of maximum summer temperatures from upper treeline sites in Interior British Columbia, Canada, Holocene, 13, 851-861, doi:10.1191/0959683603hl663rp, 2003.
Wu, X.: Tree-rings and climate change, China Meteorological Press, Beijing, 1990.

$\mathrm{Wu}, \mathrm{Y} .:$ Characteristics of Climate Changes in the Little Ice Age in China, J. Changchun Normal Univ. (Natural Sci. Ed.), 32, 74-82, 2013.

Xie, Z. and Cao, H.: Asymmetric changes in maximum and minimum temperature in Beijing, Theor. Appl. Climatol., 55, 151-56, 1996.

Yin, H., Guo, P., Liu, H., Huang, L., Yu, H., Guo, S., and Wang, F.: Reconstruction of the October mean temperature since 1796 at Wuying from tree ring data, Adv. Climate Change Res., 5, 1823, 2009.

Yin, H., Liu, H., Linderholm, H. W., and Sun, Y.: Tree ring densitybased warm-season temperature reconstruction since A.D. 1610 in the eastern Tibetan Plateau, Paleogeogr. Palaeocl., 426, 112 120, 2015.

Yu, D., Wang, Q., Wang, Y., Zhou, W., Ding, H., Fang, X., Jiang, S., and Dai, L.: Climatic effects on radial growth of major tree species on Changbai Mountain, Ann. Forest Sci., 68, 921-933, 2011.

Zhao, C., Ren, G., Zhang, Y., and Wang, Y.: Climate change of the Northeast China over the past 50 years, J. Arid Land Resour. Environ., 23, 25-30, 2009.

Zhu, H., Fang, X., Shao, X., and Yin, Z.: Tree ring-based FebruaryApril temperature reconstruction for Changbai Mountain in Northeast China and its implication for East Asian winter monsoon, Clim. Past, 5, 661-666, doi:10.5194/cp-5-661-2009, 2009.

Zhu, L., Li, S., and Wang X.: Tree-ring reconstruction of FebruaryMarch mean minimum temperature back to 1790 AD in Yichun, Northeast China, Quaternary Sci., 35, 1175-1184, 2015. 